\begin{tabular}{|} 
Ambiente \& Água - An Interdisciplinary Journal of Applied Science \\
ISSN 1980-993X - doi:10.4136/1980-993X \\
www.ambi-agua.net \\
E-mail: ambi-agua@agro.unitau.br
\end{tabular}

\title{
Quinze anos do Programa de Pós-graduação em Ciências Ambientais da Universidade de Taubaté
}

\author{
doi:10.4136/ambi-agua.1451 \\ Marcelo dos Santos Targa ${ }^{1}$; Ana Aparecida da Silva Almeida ${ }^{2}$ \\ ${ }^{1}$ Coordenador Geral dos Programas de Pós-Graduação em Ciências Ambientais/UNITAU \\ ${ }^{2}$ Coordenadora Adjunta do Programa de Pós-Graduação em Ciências Ambientais/UNITAU \\ e-mail: mtarga@unitau.br, anasilva@unitau.br
}

\section{RESUMO}

Para contribuir na formação acadêmica e científica de maneira integrada, a Universidade de Taubaté (UNITAU) criou há 15 anos o seu Programa de Pós-graduação na Área Ambiental (PPGCA). A presente edição especial da Ambi-Agua comemora esse período de trabalho apresentando 19 artigos originais oriundos de dissertações defendidas no Mestrado em Ciências Ambientais, os quais envolveram temáticas interdisciplinares diversas. Oportunamente neste editorial demonstra-se a evolução do trabalho executado no PPGCA para contribuir com o estabelecimento das ciências ambientais no Brasil.

Palavras-chave: interdisciplinaridade, mestrado, meio ambiente.

\section{Fifteen years of the graduate program of Environmental Sciences of the University of Taubaté}

\begin{abstract}
To contribute for the academic and scientific education in an integrated manner, the University of Taubate (UNITAU) created 15 years ago it's Postgraduate Program in the Environmental Area (PPGCA). The present special edition of Ambi-Agua, celebrates this work period presenting 19 original articles originated from dissertations defended on the Master's Degree in Environmental Sciences, which involved diverse interdisciplinary themes. Timely in this editorial, we demonstrate the evolution of the work executed by the PPGCA to contribute with the establishment of environmental sciences in Brazil.
\end{abstract}

Keywords: interdisciplinarity, master's degree, environment.

\section{INTRODUÇÃO}

Atualmente a Universidade de Taubaté - UNITAU, universidade pública municipal do estado de São Paulo, oferece dois Programas de Pós-graduação em Ciências Ambientais, um Mestrado na modalidade Profissional e o outro Acadêmico, os quais são resultantes da evolução do Programa de Pós-graduação em Engenharia Ambiental - Mestrado Profissional e Doutorado, implantado em 1998 na vigência da Resolução CFE no. 05/1983 que permitia o funcionamento experimental dos cursos por no mínimo dois anos previamente ao pedido de seu credenciamento ao Conselho Federal de Educação (CFE). Os trabalhos de mestrado e doutorado desenvolvidos tinham eminentemente características interdisciplinares, tanto na 
formação do corpo docente quanto na oferta de disciplinas e linhas de pesquisa estabelecidas no programa, de modo que, não possibilitava o enquadramento em apenas uma área de avaliação da CAPES - Coordenação de Aperfeiçoamento de Pessoal de Nível Superior, e sim na Área Multidisciplinar criada em 1999.

Após dois anos de funcionamento, em 2000, várias alterações foram efetuadas na estrutura do programa, como reestruturação das disciplinas, quadro docente e outras, bem como da denominação para Programa de Pós-graduação em Ciências Ambientais (PPGCA).

Com a atualização da norma brasileira para o funcionamento de cursos de pós-graduação, por meio da Resolução CNE/CES no. 1/2001, em 2003, a UNITAU optou por suspender a oferta de vagas para o doutorado, objetivando consolidar a base interdisciplinar do mestrado profissional em Ciências Ambientais. Assim, o mestrado profissional do PPGCA foi reconhecido pelo MEC-CAPES, por meio da Portaria Ministerial $\mathrm{n}^{\circ} .4 .310 / 2004$, publicada no D.O.U. de 23/12/2004, seção 1, fls. 33.

Em 2006, o curso de mestrado profissional em Ciências Ambientais da UNITAU passou a ser avaliado pela Coordenação de Área Interdisciplinar (CAInter), na Câmara Temática I Meio Ambiente e Agrárias, a primeira de quatro câmaras criadas naquele ano, para melhor atender à grande demanda de cursos de mestrado e doutorado de cunho inter e multidisciplinar.

Mesmo assim, o mestrado profissional em Ciências Ambientais tinha uma estrutura grande, com cinco linhas de pesquisa, 26 disciplinas e 30 docentes. Essa realidade era incoerente com a demanda para elevar a qualidade do curso e atingir melhor qualificação nas avaliações anuais da CAPES. Isso exigiu uma profunda reformulação na estrutura do programa, iniciada em 2007. Nessa reformulação as linhas de pesquisa existentes foram reduzidas para duas e as disciplinas foram reformuladas e melhor alinhadas com duas novas linhas, 19 disciplinas, e 23 docentes.

Em 2009, seguindo as orientações da Comissão de Visita e Acompanhamento a Programas de Pós-Graduação da CAPES, foi proposto o mestrado em Ciências Ambientais em nível Acadêmico, o qual após autorização iniciou suas atividades em 2011. O mestrado acadêmico com 12 docentes, 11 disciplinas e uma linha de pesquisa, objetiva atender às expectativas sócio-econômicas-ambientais do desenvolvimento e propor estudos relativos às modificações no uso e ocupação do solo com o crescimento de atividades industriais, urbanas e agropecuárias que envolvem o aumento no uso de energia, água, e aumento na geração de resíduos e degradação da vegetação, ou seja, os processos estruturantes da bacia hidrográfica.

Mais recentemente, além do Coordenador Geral, cada um dos mestrados ganhou um coordenador adjunto, bem como se padronizou 12 docentes permanentes para atuarem distintamente em cada um dos mestrados.

Em resposta ao processo dinâmico de discussão promovido pela Área Interdisciplinar a partir de 2004, com a instituição das Reuniões de Coordenadores de programas de PósGraduação da Área Interdisciplinar (ReCoPIs), foram propostas modificações nos procedimentos de avaliação, e face as dificuldades da avaliação conjunta dos Programas pelas quatro câmaras e ao desafio de ser a área interdisciplinar aquela que mais cresce na CAPES, foi criada, por meio da Portaria 081 de 6 de Junho de 2011, a Área de Ciências Ambientais CACIAmb (CAPES, 2011), a qual foi efetivamente instalada na I Reunião Nacional de Programas de Pós-graduação em Ciências Ambientais - $1^{\mathrm{a}}$ ReNaCiamb (CAPES, 2012). Em decorrência da necessidade de se levar em conta a complexidade dos problemas ambientais, face à indissociabilidade entre sistemas antrópicos e naturais e ao crescimento da Câmara Temática I (Targa, 2012) e, frente à real possibilidade de uma melhoria de avaliação entre os pares, os dois Programas de Ciências Ambientais da UNITAU (Profissional e Acadêmico), migraram para essa nova área de avaliação. 
O mestrado profissional, em 15 anos de existência, titulou 320 mestres e apresenta marcante vocação regional no desenvolvimento de dissertações com foco nas pesquisas científicas e tecnológicas voltadas para o Cone Leste Paulista (82\%), para a região metropolitana de São Paulo (6\%) e para outros estados (12\%). Nesse biênio de funcionamento quatro alunos se titularam no mestrado acadêmico em Ciências Ambientais.

A região do Cone Leste Paulista, e mais especificamente, o Vale do Paraíba do Sul Paulista, concentra uma ampla herança de processos diversos de desenvolvimento que se iniciaram logo no primeiro século de ocupação portuguesa do território brasileiro. Após a exploração do Pau Brasil, o primeiro ciclo de desenvolvimento foi pautado pela expansão Bandeirante e pelo ciclo da mineração, e posteriormente, pelos ciclos da cana de açúcar, da cafeicultura e da exploração leiteira e do processo de industrialização.

Essa dinâmica de ocupação e atividades produtivas com ciclos de prosperidade e decadência marca o contexto econômico e social da região, ora como centro econômico do Brasil e ora como periferia econômica e social de São Paulo e Rio de Janeiro, dinâmica que permanece ainda hoje na região, pois se por um lado São José dos Campos se apresenta como pólo tecnológico aeroespacial, que reúne centros de excelência em pesquisa e desenvolvimento, Guaratinguetá com indústrias e atividades na área química, Pindamonhangaba como pólo de reciclagem de alumínio e Taubaté como centro automobilístico e de mecânica pesada, de outro se têm as cidades, prósperas no passado, mas, que atualmente vivem da exploração de sua ruralidade e potencial turístico, tais como Cunha, Bananal, Areias, São Luiz do Paraitinga, entre outras.

É nessa região que se insere o PPGCA da UNITAU, região em que boa parte de sua área está distribuída na bacia hidrográfica do rio Paraíba do Sul, que tem sido pioneira em vários aspectos. Foi a primeira a ser intensamente utilizada na exploração hidrelétrica com cerca de 130 usinas registradas no DNPM em 1941, é pioneira na disciplina e gestão do uso dos recursos hídricos, bem como a primeira a implantar a cobrança pelo uso da água em nível federal (Johnsson et al., 2003) e uma das primeiras a implantar a cobrança em nível estadual.

Para este número especial da Ambi-Agua são apresentados 19 artigos que em síntese refletem um perfil da produção científica qualificada do Programa de Pós-Graduação em Ciências Ambientais. Cada artigo foi submetido ao tradicional e rigoroso trabalho editorial, com revisão por pares, desenvolvido na Ambi-Agua.

\section{CONSIDERAÇÕES FINAIS}

Acredita-se que esta edição especial seja uma boa amostra das atividades da UNITAU na área de Ciências Ambientais, em que o discurso científico sobre ambiente, sustentabilidade e a sobrevivência do planeta geram reflexos no papel das organizações e identificam atividades crescentes e impactantes como, dos processos de extração de areia, dos cultivos de eucalipto, do programa de biodiesel, da implantação e operação de aterros sanitários, da poluição da atmosfera, solo e água, da erosão excessiva, da reciclagem, da conservação do solo e dos cuidados com a saúde e educação da população e dos aspectos ligados à urbanização e às mudanças climáticas.

A equipe editorial agradece as contribuições de todos os profissionais comprometidos com o árduo trabalho dos PPGCAs da UNITAU na formação de recursos humanos qualificados e na produção de ciências do ambiente em nosso país. 


\section{REFERÊNCIAS}

COORDENAÇÃO DE APERFEIÇOAMENTO DE PESSOAL DE NIVEL SUPERIOR CAPES. Diretoria de Avaliação. Minuta do documento de área 2011 - Ciências Ambientais. Brasília, 2011. 50 p. Disponível em: < http://www.capes.gov.br/images/stories/download/avaliacao/49.camb_DOCUMENTO_ REA.pdf $>$. Acesso em: dez. 2013.

COORDENAÇÃO DE APERFEIÇOAMENTO DE PESSOAL DE NIVEL SUPERIOR CAPES. Diretoria de Avaliação. Documento de área 2013 - Ciências Ambientais. Brasília, 2013. 55 p. $\quad$ Disponível em: http://www.capes.gov.br/images/stories/download/avaliacaotrienal/Docs_de_area/Cienc ias_Ambientais_doc_area_e_comiss\%C3\%A3o_block.pdf $>$. Acesso em: dez. 2013.

COORDENAÇÃO DE APERFEIÇOAMENTO DE PESSOAL DE NIVEL SUPERIOR CAPES. Diretoria de Avaliação. Relatório da reunião de coordenadores dos programas de pós graduação em Ciências Ambientais. Brasília, 2012. Disponível em:<http://www.capes.gov.br/images/stories/download/avaliacao/Relatorio_Reuniao_C oordenadores_Ciencias_Ambientais2.pdf>. Acesso em: dez. 2013.

COORDENAÇÃO DE APERFEIÇOAMENTO DE PESSOAL DE NIVEL SUPERIOR CAPES. Diretoria de Avaliação. Documento de área 2013 - Interdisciplinar. Brasília, 2013. 86 p. $\quad 20$ Disponível <http://www.capes.gov.br/images/stories/download/avaliacaotrienal/Docs_de_area/Inter disciplinar_doc_area_e_comiss\%C3\%A3o_block.pdf>. Acesso em: dez. 2013.

JOHNSSON, R. M. F. et al. A construção do pacto em torno da cobrança pelo uso da água na bacia do rio Paraíba do Sul. In: SIMPÓSIO BRASILEIRO DE RECURSOS HÍDRICOS, 15., 2003, Curitiba. Anais... Rio de Janeiro: ABRH, 2003.

TARGA, M. S. Reflections on the prospects for evaluation and qualified production or graduate programs in the environmental Sciences. Revista Ambiente \& Água, Taubaté, v. 7 , n. 1, p. 4-8, 2012. http://dx.doi.org/10.4136/ambi-agua.879 